\title{
Making the most of secure water: a framework to aid decision making
}

\author{
$\underline{\text { S. Shahpari }}^{\text {a }}$, J. Allison ${ }^{a}$, R.A. Stanley ${ }^{b}$ and M.T. Harrison ${ }^{\text {c }}$ \\ ${ }^{a}$ Institute for Regional Development, University of Tasmania, Tasmania, Australia. \\ ${ }^{b}$ Centre for Food Innovation, University of Tasmania, Tasmania, Australia. \\ ${ }^{c}$ Tasmanian Institute of Agriculture, School of Land and Food, University of Tasmania, Tasmania, Australia. \\ Email: Sahar.shahpari@utas.edu.au
}

\begin{abstract}
Decision-making on agricultural land-use in Tasmania is a very complex process that involves consideration of opportunities generated from the expansion of irrigation to meet agricultural water demands and mitigate climatic risks to crop yields. Tasmania Irrigation (a State Government owned company) is interested in attracting farmer investment to new water schemes. Tasmanian farmers are concerned about production choices that might maximize investment returns when buying into irrigation schemes. In this context of increased water security and changing crop values, farmers and other decision makers need a framework to guide investment decisions.
\end{abstract}

Geo-spatial Agent-Based modelling (ABM) has potential for representing the dynamic processes in decisionmaking and agricultural systems. It allows for a flexible use of tools and modelling techniques particularly in relation to geospatial modelling. Agent Analyst is a free and open source extension recently developed by ESRIArcGIS to be implemented as a new model-tool type of ABM to analyze the spatial relationships of agents. It has the potential to create agents ${ }^{1}$ from GIS layers and execute the agent behavior rules with display of the result of the simulation within the ArcGIS environment. Advances in Agent Analyst allow creating, editing, and running Repast models from within the ArcGIS 10 Geoprocessing framework. As a result, Agent Analyst is a useful tool for analyzing the decision making process and simulating actions of farmers and measuring the resulting system behaviors and outcomes.

This paper covers the development of an agent based model using Agent Analyst software to study the consequences of changes in patterns of both land use and water use over time in the Dorset region of Northern Tasmania. Dorset has been a region undergoing significant change from commodity based production to higher value added production with access to guaranteed water and opportunities to consider new and alternative crops. Agent Analyst offers a way of taking into account decision-making on agricultural land use at different levels by taking advantages of ABM within ArcGIS modelling environment. The paper illustrates the types of information that can be generated in order to support farmers' decision with respect to irrigation expansion.

${ }^{1}$ Agents could be farmers, buildings, land parcels, stakeholders.

Keywords: Agricultural land-use, geo-spatial agent-based modelling, agent analyst, irrigation 


\section{INTRODUCTION}

Tasmania's economic strengths lie in natural assets including the availability of clean energy, varying soil types and water for agricultural expansion. Tasmania is also expected to experience less severe climate change impacts compared to other parts of Australia due to its temperate maritime climate (Hennessy and Flagship, 2008). Agriculture plays an important role in the State economy and contributes about 18 percent of gross State product and one in six jobs (TFGA, 2011). Around 12 per cent of the Australia's fresh water resources are in Tasmania which has around 3 per cent of the nation's population. As a result, Tasmania's approach to land and water use is complicated and different to the rest of Australia as evidenced in different plans and schemes ${ }^{2}$ ((RDA), 2014, TCCO, 2012, TFGA, 2011).

While there is a strong and positive future for agriculture in Tasmania, there are some challenges such as increasing risk of climate changes, a growing global and national competitive market for agricultural products, and an increase of exceptionally hot and dry years. While Tasmanian agriculture is privileged to experience a generally reliable rainfall, there are periods when rainfall is significantly below or above the average and access to water in some agricultural regions is limited. Water availability and security is critical to agriculture development in the long term. So, it is important to make informed decisions on a regional scale to not only better manage and distribute the water resources in Tasmania but also to extract the highest and best value from each litre of water conserved.

The debate over the best way to maximize benefits from fertile soils, reliable rainfall and sunshine sits at the center of considerations about the future of Tasmania. The issues for Tasmanian Irrigation about water concentrate on how they can improve the water-use efficiency to sustain agricultural production, add value to water trading and how to attract farmer investment through the water sale period in setting up an irrigation scheme. Debates for Tasmanian agriculture focus on that how farmers can utilize water and land to produce the best high value crops and cover the costs of freights, wages and water. A further issue is how the codependence between agricultural products and processers can lead to economic growth in Tasmania.

Decision-making on water and land use in Tasmania is a very complex process and involves consideration of social, economic and environmental values. With regards to strengths and challenges in Tasmania, there is potential for agriculture to grow in all regions with the development of new irrigation schemes (TFGA, 2011)). The aim of this paper is to develop an advanced framework for making decisions about land and water use in the context of expanded irrigation coverage in the State. The study argues that it would be cost effective to use computer-based simulation models to predict the consequences of a range of different irrigated agricultural land-use scenarios prior to making critical regional decisions about water and land use. Specifically, the study will use a case study region in Tasmania the Dorset region which has accessed expanded irrigation options as the vehicle to examine farmer decision making as to highest and best value for alternative crops with changed water regimes.

\section{DORSET REGION}

Dorset region is in North East of Tasmania with an area of approximately 3,200 square kilometers ${ }^{4}$ and a population of around 7,200 people. The region has supported small settlements throughout its history and the median age in this region is around 46 years. People have lived on the Dorset region supported mainly by agriculture, forestry and fishing industry. There are more than five catchments in the Dorset region and the Great Forest-Bird catchment has been chosen as a case study within the region because this has been a catchment experiencing change from traditional crops to higher value added production with access to guaranteed water and there are opportunities for the region to consider new alternative crops.



Figure 1. Dorset Region

\footnotetext{
${ }^{2}$ http://www.abc.net.au/news/2014-03-14/tasmania-agri-politics/5321580

${ }^{3} \mathrm{http} / / /$ www.abc.net.au/news/2014-10-23/no-water-sales/5913966

${ }^{4} \mathrm{http}: / /$ maps.thelist.tas.gov.au/listmap/app/list/map
} 


\section{DECISION MAKING SUPPORT SYSTEMS: MACRO LEVEL OR MICRO LEVEL?}

Decision-making on water and land use in Tasmania is not just farm planning on a different scale. It is a very complex process that involves consideration of irrigation expansion to meet agricultural water demands in both regional scale (macro level) and farm scale (micro level). According to Cabrera et al. (2010, p.1) "small changes in micro level decision-making methods used by agents may significantly affect macro level outcome".

Taking the region as a whole and integrating different bodies of knowledge such as economics, social science and information technology to make an appropriate decision and design a new plan for the best future, can be a complex process. In such circumstances, there is a need for a framework to reduce the complexity of the decision making process to a manageable level. Therefore for making decisions on a regional scale we rely on a scientific framework and use of computer-based simulation models and there are different decision support techniques and frameworks to assess land and water use options on the regional scale (Hajkowicz et al., 2000).

In Australia, Multiple-Criteria Decision Analysis (MCDA) was identified by the Resource Assessment Commission (Commission, 1993) as a method for making strategic environmental decisions. Based on this technique, different software have been developed for making decisions at the macro level. For example, the Catchment Decision Assistant (CDA) (Itami et al., 2001), Multi-Criteria Analysis Shell (MCAS-S)(Hill et al., 2005). Although GIS- Based MCDA (spatial MCDA) was developed as a process to combine geographical data and value judgments (the decision-maker's preferences), its lack of transparency to the end user has raised concerns. A main criticism of MCDA tends to focus on the complex mathematical sophistication of some of the MCDA techniques, the impact of weights on the results of MCDA at the macro level (Hajkowicz et al., 2000) and the uncertainty in the micro level of decision making.

In last two decades, the notion that models of geographic systems should be tested at the individual (micro) levels with 'agents' has become the focus of spatial structure analysis. As Batty et al. (2012, P.2) described "Agents generate actions that occur in time as well as space, that influence their wider environments and that cooperate as well as conflict with one another over the use of space." Agents could be people of the place, buildings, cars, land parcels, stakeholders, home seekers and decision makers. According to this definition, agents behave individually and make decisions at the micro level and their behavior can be tracked over time (Steinitz, 2012). Moreover, they have relationships with each other and their decisions influence their wider environment. The focus on agents in the spatial context addresses some of the concerns expressed about multi-criteria decision analysis leading to the development of spatially located agent based models.

Agent-Based Models (ABM) are rule-based approaches and rules are typically based around 'if-else' statements (Steinitz, 2012). Agent-based models are useful for relating the heterogeneous behavior of agents with different information, different decision rules, and different situations (Lempert, 2002). ABM has the potential to represent dynamic processes in a complex system such as decision-making systems. Furthermore it is a flexible approach, particularly in relation to geospatial modelling. The inherent flexibility (Johnston, 2013) and visualization in ABM's are the most effective way to communicate key model information (North and Macal, 2007) and spatial relationships can become an integral part of the decision making of the agents. The notion of agent-based models in geographical system is timely due to the increasing ability of computation for handling agent data to calculate interactions and build models. ABM offers a way of taking into account decision-making by assuming all members of class or group behave individually instead of identically (Steinitz, 2012). Based on this characteristic the research hypothesizes that the behavior of agricultural land users can be influenced by dynamic events such as irrigation expansion at very different time scales.

\subsection{Spatial Agent based model}

The history of computational agent-based modelling $(\mathrm{ABM})^{5}$ goes back to Stanislaw Ulam's cellular automata (CA) as a simple time-stepped model (Wolfram, 2002). In terms of using ABM for social science, Schelling (1971) introduced a model of housing segregation. Due to the convergence of object-oriented programming ideas in computer science, researchers such as Robert Axelrod (1997) have looked at simple strategic interactions. Parker et al. (2003) studied land-use and land cover changes by combining spatial information with dynamic agent-based models and most recently, there has been an explosion in number of successful ABM applications (Johnston, 2013).

\footnotetext{
${ }^{5} \mathrm{ABM}$ is also taken to mean Agent-Based Model (s) as well as Modelling.
} 
The impact of policy on geographical areas has also been investigated through ABM, for example education planning (Harland and Heppenstall, 2012). More detail on the history of agent-based modelling can be found in Macal and North (2009).

As Crooks and Heppenstall (2012, P.89-90) explained "agents can possess rules that will affect their behavior and relationships with other agents and /or their surrounding environment". Agents behave in a rule-based structure and the rules are based on expert knowledge, data analysis and published literature. The agent alters the attributes of its current location or its environment based on exploiting resources at its current location, altering the state of the location (e.g. changing the land use) or, perhaps simply updating its current 'map' of the environment(O'Sullivan et al., 2012).

\subsection{Software considerations}

$\mathrm{ABM}$ is flexible for handling of time but it is also relatively appropriate for representing changes in space (Brown et al., 2005). Agents make decisions relative to their locations during periods of time. They can interact with the landscape and their surrounding environment and influence the other agents' decisions. GIS is a platform that brings all of the spatial relationships in an integrated spatial form and has the characteristic of being digital, visual, analytic and quantitative. There is a natural synergy between ABM and a GIS and Agent Analyst software was developed to integrate the Recursive Porous Agent Simulation Toolkit (RePAST) (North et al., 2006) within ArcGIS Software in order to maximize these synergies (Johnston, 2013).

Agent based modeling in GIS is presented as an ESRI Agent Analyst software which is built on the programming language called Not Quite Python. Agent Analyst focuses on a middleware approach to link the object-oriented ABM and ArcGIS software systems to provide a mapping from one system to the other. It is able to effectively represent both the complex spatial structures in GIS and the rich dynamical processes of ABM. It gives the ArcGIS user more flexibility and direct access from coding environment to a GIS data base and visualization environment (Johnston, 2013).

Identity relationships, Causal relationships, temporal relationships, and topological relationships are the four key relationships between agent-level processes and spatial data. Based on these relationships, there are three approaches for developing a model that influence the integration of a dynamic GIS data base and an ABM process model. These are summarized as follows:

- ABM-centric approaches have involved the use of software libraries of GIS functions within ABMs.

- GIS-centric approaches have implemented ABM functions and models within a GIS system and allow such models to run interactively within the graphical user interface of the GIS package

- A Middleware approach is centred on both ABM and GIS for developing a software to handle the identity and causal relationships between the agents within an ABM environment and the temporal and topological relationship (spatial features) within a GIS environment (Brown et al., 2005, Brown and Robinson, 2006).

\section{METHODOLOGY}

In the implementation of Spatial ABM a fundamental and basic problem relates to the rules underpinning the model best stated as: "How do we identify a set of rules and computer algorithms for developing ABM model and get to the best possible future?" Clearly a process is needed to (1) generate these rules and (2) apply the rules so that the model can be operationalized. Recently, Harvard University Professor Carl Steinitz (2012) has developed a Geodesign framework that provides a structured process for making decisions and designing alternative futures at different scales. The Geodesign framework is a collaborative framework adopted as a useful approach for understanding the issues and requirements posed by the people in a region, in order to specify a set of formal rules for developing the ABM. In Steinitz's approach he proposes, there are three iterations or steps needed for designing alternative futures. This three step process is adopted as the methodological framework of this study looking at best futures and value for irrigated land in the Dorset Region.

\subsection{Identify the rules and agents}

In the first step, the focus is to collect data and develop possible scenarios by involving stakeholders in defining the assumptions about the future (Stakeholder-defined scenarios). This involves interviewing stakeholders about their criteria for making decisions on land and water use options and the integration of that information with maps of possible changes in land use. 
This iteration is designed to help investigate the personal and cultural values and institutional knowledge of farmers and other stakeholders (e.g. Tasmania Irrigation), who are highly influential in the future of land and water use in the Dorset region. This stage also helps to investigate the relative level of importance of individual's criteria and value for making decision about investing in irrigation schemes. Furthermore, , it helps to extract their priorities about the alternative crops and added value processing with respect to irrigation expansion.

\subsection{Analysing options and alternatives}

In the second step of the Steinitz framework the process involves defining the methods and design models required to analyze the scenarios and calculate alternative outcomes. At this point it is proposed Spatial Agent Base Modelling will be used to predict the consequences of a range of different irrigated agricultural land-use and value-add scenarios. These will be defined based on cultural values, logical values, and rational values to predict the future of the region that include judgments made by people gained form the interviews and survey conducted in the first phase.

\subsection{Macro and micro decision making \& agent based modelling}

In the third iteration, the models designed during the second iteration will be implemented. ABM can be used for running and observing agent's decisions on a macro level (region) and on a micro level (farm land). The attributes and behaviour of agents can be simulated in the GIS environment over the course of multiple simulation runs (Brown and Robinson, 2006). The GIS-based ABM is able to "simulate individual actions of many diverse agents and measure the resulting system behaviour and outcomes over time"(Castle and Crooks, 2006, p.11) (e.g. changes in patterns of land-use and water- use for cultivating alternative crops ). As a result, it is a useful model for studying the alternative options of crops and added value processing with regards to irrigation expansion in Tasmania. By adopting this framework, we will be able to study that applicability of the agents' behaviors on both macro level and micro level of the decision making process.

\section{DISCUSSION: FARMERS' DECISION-MAKING AND THE EXPANSION OF IRRGATION}

Farmers make decisions about what to grow, where to grow and how much water they need((FAO), 1993). Their decisions are firstly made based on the opportunities that are available in their region (e.g. irrigation expansion scheme), and then according to their knowledge of the land, their experiences and the technology. Creating an agent-based model for making a decision about water expansion in the Dorset region requires an in-depth understanding of decision-making process on agricultural land use and water use. As the Figure 2 shows, Tasmania Irrigation makes decisions about water and irrigation expansion on the macro scale. Their decisions made on the macro level affect farmers' decisions on the micro level. On the other hand, farmers decide to invest and buy the irrigation scheme and their decision in micro level influence the future of irrigation expansion in the region. As a result, there is a relationship between the agents' behavior and agents' decision about water and land use options in the region. By adopting GIS based-ABM, we will be able to study and calculate agents' behaviors as a function of different rules in the Dorset region.

We assume that Farmer Agents own Parcels of land (which are part of the Landscape), that the agent's past history and knowledge contribute to its future decisions, and that there are spatial allocations which can be looked at as rules with spatial components (Murray-Rust et al., 2014). The decisions of farmers are made in the context of land and water, which leads to the specific rules which they use to make their decisions. There are two groups of rules that affect their decision.

1. Rules are based on policy potential and opportunities in the region (e.g. irrigation infrastructure) and physical constraints (e.g. land capability). These rules are based on what the farmers can and can't do. It directly affects the farmer's decisions for investing in an irrigation scheme and offers encouragement in the form of subsidies for certain behaviours. These rules are mostly the consequences of decision making in macro level or physical constraints. The point is that farmers cannot change these rules but they can adjust them. As a quick overview, these are: 
- The size of parcel determines the tendency to invest in irrigation scheme.

- The land capability determines the amount of water they need to overcome the constraints ( such as soil, slopes,...) and to improve the productivity

- The presence of irrigation determines the ability to improve the productivity of land

- The access to electricity determines the feasibility of using irrigation.

2. Rules are based on farmers' knowledge of land and water, their personal and cultural values and their experiences. These rules are defined and weighted by their priorities about the alternative crops and added value processing with respect to irrigation expansion. The point is that the farmers can change these rules to suit themselves. As a result, we will develop these rules by interviewing and analyzing questionnaires to investigate the relative level of importance of their criteria and value for making decision about investing in irrigation schemes. As a quick overview, these are:

- The market determines prices for selling crops, and costs associated with growing crops

- The irrigation demand for producing alternative crops determines the amount of water trading

- Added value processing determines the alternative crops with specific use in the region

- Neighbours and the surrounding fields determine the social network for new alternative crops

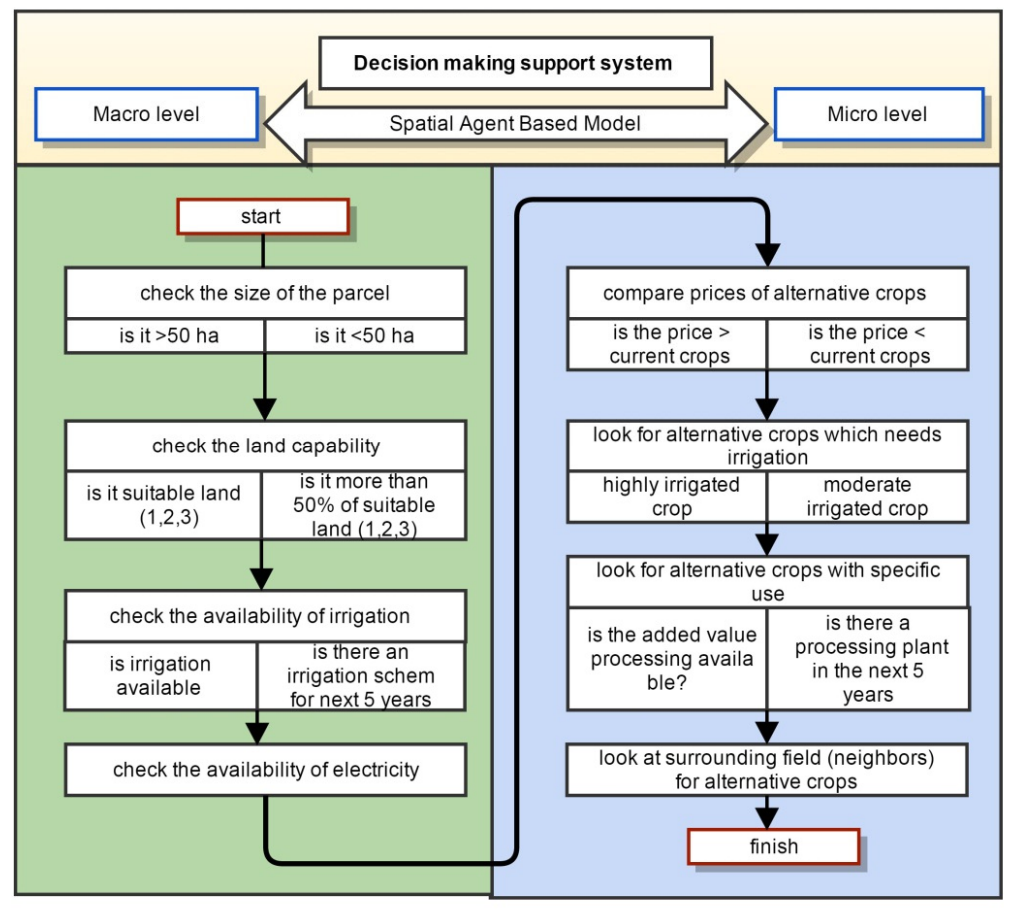

Figure 3. Spatial Agent Based Modelling of irrigation expansion

\section{CONCLUSION}

In this paper, we have presented an overview of the concept of using GIS based-ABM to study farmers' decisions with regards to irrigation expansion in the Dorset region. We will use Agent Analyst software which has synchronized ABM with Arc GIS to show the effects of changing the agent rules through maps and visualization. Agent Analyst's approach is Middleware which is centered on both ABM and GIS to handle the relationship between agents within the ABM environment and spatial relationship within the GIS environment. By combining the qualitative data from the interview and questionnaires, we will be able to define rules and develop an ABM model which is more representative of the individual agent's knowledge and styles of agents' thinking in the GIS environment. 


\section{REFERENCES}

(FAO), F. A. O. 1993. Guidelines for Land-use Planning, Agriculture Organization of the United Nations. Soil Resources Conservation Service, Food \& Agriculture Organization.

(RDA), R. D. A. T. C. 2014. RDA Tasmania Regional Plan. July 2013- June 2016. Tasmania: RDA Tasmania Committee and Department of Infrastructure and Regional Development.

AXELROD, R. M. 1997. The complexity of cooperation: Agent-based models of competition and collaboration, Princeton University Press.

BATTY, M., CROOKS, A. T., SEE, L. M. \& HEPPENSTALL, A. J. 2012. Perspectives on agent-based models and geographical systems. Agent-Based Models of Geographical Systems. Springer.

BROWN, D. G., RIOLO, R., ROBINSON, D. T., NORTH, M. \& RAND, W. 2005. Spatial process and data models: Toward integration of agent-based models and GIS. Journal of Geographical Systems, 7, 25-47.

BROWN, D. G. \& ROBINSON, D. T. 2006. Effects of heterogeneity in residential preferences on an agentbased model of urban sprawl. Ecology and society, 11, 46.

CABRERA, A. R., , P. J. D. \& , E. S. B. A. M. P.-V. 2010. Exploring the Choice of Decision Making Method in an Agent Based Model of Land Use Change. International Environmental Modelling and Software Society (iEMSs). Ottawa, Canada.

CASTLE, C. J. \& CROOKS, A. T. 2006. Principles and concepts of agent-based modelling for developing geospatial simulations.

COMMISSION, A. R. A. 1993. Coastal zone inquiry final report, The Commission.

CROOKS, A. T. \& HEPPENSTALL, A. J. 2012. Introduction to agent-based modelling. Agent-based models of geographical systems. Springer.

HAJKOWICZ, S., YOUNG, M. \& MACDONALD, D. H. 2000. Supporting decisions: understanding natural resource management assessment techniques. Policy and Economic Research Unit, CSIRO Land and Water, Adelaide, Australia.

HARLAND, K. \& HEPPENSTALL, A. J. 2012. Using Agent-Based Models for Education Planning: Is the UK Education System Agent Based? Agent-based models of geographical systems. Springer.

HENNESSY, K. J. \& FLAGSHIP, C. A. 2008. An assessment of the impact of climate change on the nature and frequency of exceptional climatic events, Department of Agriculture, Fisheries and Forestry.

HILL, M. J., LESSLIE, R., BARRY, A. \& BARRY, S. A simple, portable, spatial multi-criteria analysis shell-MCAS-S. MODSIM 2005 International Congress on Modelling and Simulation. Modelling and Simulation Society of Australia and New Zealand, 2005. 12-15.

ITAMI, R. M., MACLAREN, G. \& HIRST, K. 2001. Integrating the AHP with geographic information systems for assessing resource conditions in rural catchments in Australia. The analytic hierarchy process in natural resource and environmental decision making. Springer.

JOHNSTON, K. M. 2013. Agent analyst: agent-based modeling in ArcGIS. Redlands, CA: Esri Press.

LEMPERT, R. 2002. Agent-based modeling as organizational and public policy simulators. Proceedings of the National Academy of Sciences of the United States of America, 99, 7195-7196.

MACAL, C. M. \& NORTH, M. J. Agent-based modeling and simulation. Winter Simulation Conference, 2009. Winter Simulation Conference, 86-98.

MURRAY-RUST, D., ROBINSON, D. T., GUILlEM, E., KARALI, E. \& ROUNSEVELL, M. 2014. An open framework for agent based modelling of agricultural land use change. Environmental Modelling \& Software, 61, 19-38.

NORTH, M. J., COLLIER, N. T. \& VOS, J. R. 2006. Experiences creating three implementations of the repast agent modeling toolkit. ACM Trans. Model. Comput. Simul., 16, 1-25.

NORTH, M. J. \& MACAL, C. M. 2007. Managing business complexity: discovering strategic solutions with agent-based modeling and simulation, Oxford University Press.

O’Sullivan, D., MillingtON, J., PERRY, G. \& WAINWRIGHT, J. 2012. Agent-Based ModelsBecause They're Worth It? Agent-based models of geographical systems. Springer.

PARKER, D. C., MANSON, S. M., JANSSEN, M. A., HOFFMANN, M. J. \& DEADMAN, P. 2003. Multiagent systems for the simulation of land-use and land-cover change: a review. Annals of the association of American Geographers, 93, 314-337.

SCHELLING, T. C. 1971. Dynamic models of segregation †. Journal of mathematical sociology, 1, 143-186.

STEINITZ, C. 2012. A framework for Geodesign: changing geography by design, esri.

TCCO 2012. Adapting to Climate Change in Tasmania - Issues Paper. Hobart, Tasmania: Tasmanian Climate Change Office.

TFGA, S. T. 2011. Industry skills plan: Agriculture July 2011-June 2014. Tasmania: Hobart RDS Partners Pty Ltd

WOLFRAM, S. 2002. A new kind of science, Wolfram media Champaign. 